\title{
FATORES DETERMINANTES DO NÍVEL DE DISCLOSURE VOLUNTÁRIO DAS COMPANHIAS ABERTAS NO BRASIL
}

\author{
FACTORS DETERMINING VOLUNTARY DISCLOSURE LEVEL OF \\ PUBLICLY TRADED COMPANIES IN BRAZIL
}

\section{FACTORES DETERMINANTES DEL NIVEL DE DISCLOSURE VOLUNTARIO DE LAS COMPAÑÍAS ABIERTAS EN EL BRASIL}

\author{
FERNANDO DAL-RI MURCIA \\ Doutorando em Contabilidade - Universidade de São Paulo \\ murcia@usp.br
}

\section{ARIOVALDO DOS SANTOS}

Professor Titular do Departamento de Contabilide e Atuária da Universidade de São Paulo arisanto@usp.br

\section{RESUMO}

O objetivo do estudo é identificar os fatores que explicam o nível de disclosure voluntário das companhias abertas no Brasil. A pesquisa está fundamentada na Teoria do Disclosure Voluntário de Verrecchia (2001). O nível de disclosure das empresas foi definido a partir de uma métrica composta por seis categorias e 43 subcategorias: Ambiente de Negócios (8), Atividade Operacional (8), Aspectos Estratégicos (8), Informações Financeiras (7), Índices Financeiros (4) e Governança Corporativa (8). A análise do disclosure voluntário foi realizada a partir das Demonstrações Financeiras Padronizadas (DFPs), do exercício findo em 2007, por meio da técnica de análise de conteúdo. A amostra é composta pelas 100 maiores companhias abertas não-financeiras. Por meio de um modelo de regressão múltipla, foram testadas nove hipóteses: auditoria, rentabilidade, internacionalização, tamanho, governança corporativa, endividamento, controle acionário, emissão de ações e setor. Os resultados evidenciam que empresas maiores, pertencentes ao setor elétrico, que possuem American Depositary Receipts (ADRs) nos níveis II e III na Bolsa de Nova lorque (NYSE) e que aderem aos níveis diferenciados de governança corporativa da Bolsa de São Paulo (Bovespa), pos- 


\section{repec}

suem, em média, um maior nível de disclosure voluntário. Esses resultados podem ser interpretados à luz da hipótese do vínculo (bonding hypothesis) e também dos custos políticos (political costs hypothesis), na medida em que grandes empresas e aquelas com melhores práticas de governança corporativa possuem maiores níveis de disclosure voluntário. Notase também que a regulação setorial, especificamente no setor elétrico, também é um fator significativo para explicar o nível de disclosure voluntário das companhias abertas.

Palavras-chave: Nível de Disclosure, Teoria do Disclosure Voluntário, Companhias Abertas.

\section{ABSTRACT}

The objective of the study is to identify the factors explaining voluntary disclosure level of publicly traded companies in Brazil. The research is based on Verrecchia's Voluntary Disclosure Theory (2001). Companies' disclosure level was defined from metrics composed of six categories and 43 subcategories: Business Environment (8), Operational Activity (8), Strategic Aspects (8), Financial Information (7), Financial Indexes (4) and Corporate Governance (8). The analysis of voluntary disclosure was performed based on the Standard Financial Statements from the fiscal year which ended in 2007, through content analysis technique. The sample is composed of the 100 largest non-financial publicly traded companies. Using a multiple regression model, nine hypotheses were tested: audit, profitability, internacionalization, size, corporate governance, indebtedness, share control, stock issue and industry. Results show that larger electric power companies with American Depositary Receipts (ADRs) at levels II and III in the New York Stock Exchange (NYSE), which adopt different levels of Sao Paulo Exchange's (Bovespa) corporate governance, present, on average, a higher level of voluntary disclosure. These results can be interpreted in the light of bonding hypothesis and also political costs hypothesis, as larger companies and those with best practices regarding corporate governance show higher levels of voluntary disclosure. It is also possible to note that sector regulation, especially in the electric power sector, is also a significant factor to explain the level of voluntary disclosure of publicly traded companies.

Keywords: Disclosure Level, Voluntary Disclosure Theory, Publicly Traded Companies.

\section{RESUMEN}

El objetivo del estudio es identificar los factores que explican el nivel de disclosure voluntario de las compañías abiertas en el Brasil. La pesquisa está fundamentada en la Teoría del Disclosure Voluntario de Verrecchia (2001). El nivel de disclosure de las empresas fue definido a partir de una métrica compuesta por seis categorías y 43 subcategorías: Am- 
biente de Negocios (8), Actividad Operacional (8), Aspectos Estratégicos (8), Informaciones Financieras (7), Índices Financieros (4) y Gobernación Corporativa (8). El análisis del disclosure voluntario fue realizado a partir de las Demostraciones Financieras Estandarizadas (DFPs), del ejercicio finalizado en 2007, por medio de la técnica de análisis de contenido. La muestra está compuesta por las 100 mayores compañías abiertas no financieras. Por medio de un modelo de regresión múltiple, fueron testadas nueve hipótesis: auditoría, rentabilidad, internacionalización, tamaño, gobernación corporativa, endeudamiento, control accionario, emisión de acciones y sector. Los resultados evidencian que empresas mayores, pertenecientes al sector eléctrico, que poseen American Depositary Receipts (ADRs) en los niveles II y III en la Bolsa de Nueva York (NYSE) y que se adhieren a los niveles diferenciados de gobernación corporativa de la Bolsa de São Paulo (Bovespa), poseen, en promedio, un mayor nivel de disclosure voluntario. Esos resultados pueden ser interpretados a la luz de la hipótesis del vínculo (bonding hypothesis) y también de los costes políticos (political costs hypothesis), en la medida en que grandes empresas y aquellas con mejores prácticas de gobernación corporativa poseen mayores niveles de disclosure voluntario. Se nota también que la regulación sectorial, específicamente en el sector eléctrico, también es un factor significativo para explicar el nivel de disclosure voluntario de las compañías abiertas.

Palabras clave: Nivel de Disclosure, Teoría do Disclosure Voluntario, Compañías Abiertas.

\section{INTRODUÇÃO}

A assimetria informacional entre controladores e usuários externos cria a demanda para o disclosure corporativo (FRANCIS; NANDA; OLSON, 2008), que pode ser visto justamente como o canal de transmissão das informações da empresa para o mercado (ZHANG, 2008). De acordo com Baums (2002), o disclosure tem uma função facilitadora: é realizado de forma a auxiliar o processo decisório do usuário.

Nota-se que, desde o escândalo da Enron nos Estados Unidos, o disclosure tem recebido ainda mais atenção (AKHTARUDDIN, 2005). Nessa mesma linha de pensamento, percebe-se que a crise da subprime nos Estados Unidos também levantou questões acerca da correta divulgação das operações de securitização das empresas do setor financeiro. De acordo com Shin (2003), uma das políticas que vêm sendo utilizadas pelos órgãos reguladores nos momentos de crise e turbulência nos mercados internacionais é exatamente o aumento do disclosure corporativo.

Neste cenário, a Contabilidade exerce um papel extremamente importante, pois as demonstrações contábeis são a principal forma de disclosure das informações corporativas (BRAVO; ABAD; TROMBETTA, 2008). De acordo com o ex-presidente da Security Exchange Comission (SEC), "o sucesso de um mercado de capitais é diretamente dependente da 
qualidade das normas contábeis e de disclosure, pois esses fornecem confiança aos investidores de que as demonstrações contábeis são confiáveis" (LEVITT, 1988, p. 80).

De maneira geral, nota-se que o disclosure de algumas empresas excede o requerido por lei (LANG; LUNDHOLM, 1993). Isso ocorre porque os controladores da empresa (gestores ou acionistas majoritários) geralmente possuem informações adicionais cuja divulgação não é obrigatória e, em certos casos, decidem divulgá-la (VERRECCHIA, 2001).

Evidências empíricas apontam que empresas com melhor disclosure possuem menor custo de capital próprio (BOTOSAN, 1997; HAIL, 2003; FRANCIS; KRURANA; PEREIRA, 2005; ALENCAR, 2007), menor custo de capital de terceiros (SENGUPTA, 1998; LIMA, 2007), aumento da liquidez das ações da empresa (WELKER, 1995; HEALY; HUNTTON; PALEPU, 1999; LEUZ; VERRECCHIA, 2000) e aumento do acompanhamento por parte dos analistas (HEALY; HUNTTON; PALEPU, 1999; LANG; LUNDHOLM, 2000).

Contudo, o disclosure voluntário também acarreta custos para a empresa como, por exemplo: custos de preparação e certificação (auditoria) das demonstrações contábeis, custos de oportunidade do pessoal envolvido nesse trabalho (LEUZ; WYSOCKI, 2008), custos de propriedade (VERRECHIA, 2001) e, especificamente no Brasil, os custos de publicação das demonstrações contábeis no Diário Oficial do Estado e em jornais de grande circulação.

Assumindo uma perspectiva de racionalidade econômica e dado que existem benefícios e custos com o disclosure voluntário de informações, a Teoria da Divulgação baseada no Julgamento, também conhecida como a Teoria do Disclosure Voluntário, provê o arcabouço conceitual para examinar os incentivos que os gestores e/ou as empresas têm para divulgar informações de maneira voluntária (VERRECHIA, 2001). A premissa central é de que o disclosure voluntário só ocorre quando há mais benefícios do que custos para os gestores e/ou as empresas (DYE, 2001).

Mais especificamente, essa teoria fornece subsídios teóricos e analíticos para se verificar em que circunstâncias os gestores estariam dispostos a divulgar de maneira voluntária (ou não divulgar) determinadas informações (YAMAMOTO; SALOTTI; 2006). Nessa linha de pensamento, a evidenciação de informações voluntárias pode ser explicada por características da própria empresa, tais como porte, desempenho, práticas de governança corporativa, etc. (CUNHA; RIBEIRO, 2006).

Trabalhos que buscaram explicar o nível de disclosure voluntário, a partir das características das empresas, já foram realizados em diversos países, como por exemplo: Bangladesh (AHMED; NICHOLLS, 1994;) França (DEPOERS, 2000), Hong Kong (WALLACE; NASER, 1995), Japão (COOKE, 1992), Malásia, (HOSSAIN; TAN; ADAMS, 1994), México (CHOW; WONG-BOREN, 1987), Republica Checa (PATTON; ZELENKA, 1997), Suécia (COOKE, 1989) e Suíça (RAFFOUNIER, 1995).

Já no cenário nacional, nota-se a ausência de estudos fundamentados na Teoria do Disclosure Voluntário, que busquem fornecer explicações para o fenômeno da divulgação 
voluntária de informações. Assim, o presente trabalho visa preencher essa lacuna e possui o seguinte problema de pesquisa:

\section{Quais Fatores Explicam o Nível de Disclosure Voluntário das Companhias} Abertas no Brasil?

\section{FUNDAMENTAÇÃO TEÓRICA}

Com o objetivo de explicar as razões que levam empresas a divulgar voluntariamente uma informação, alguns pesquisadores têm buscado desenvolver modelos analíticos, com premissas econômicas, que objetivam fornecer um arcabouço teórico para o desenvolvimento de pesquisas sobre o tema. O objetivo desses modelos é estabelecer um link entre a divulgação contábil e suas consequências, já que sem uma motivação econômica o estudo do disclosure fica sujeito apenas a opiniões. Dentre esses modelos, merece destaque o trabalho de Verecchia (2001), o qual categorizou o disclosure em três grandes grupos:

- Divulgação baseada em Associação (Association-based Disclosure): buscase examinar a relação e os efeitos dos disclosure nos agentes durante o evento do disclosure.

- Divulgação baseada em Eficiência (Efficiency-based Disclosure): objetiva-se analisar se existem arranjos eficientes no disclosure que seriam preferidos incondicionalmente.

- Divulgação baseada em Julgamento (Discretionary-based Disclosure): analisa-se a discricionariedade que os gestores exercem com relação às decisões de disclosure.

O presente trabalho, em razão do seu objetivo de pesquisa, fundamenta-se na Divulgação baseada em Julgamento, que, de acordo com Yamamoto e Salotti (2006), é conhecida como Teoria do Disclosure Voluntário. A premissa central dessa teoria é de que o disclosure é um evento endógeno, sendo que os gestores e/ou as empresas possuem incentivos econômicos para divulgar, ou não, informações de maneira voluntária, uma vez que os usuários externos das demonstrações contábeis são os consumidores dessas informações (VERRECCHIA, 2001).

De acordo com Dye (2001), essa teoria é um caso especial da Teoria dos Jogos, a qual a principal premissa é a de que a entidade só divulgará voluntariamente informações favoráveis. O raciocínio é que o disclosure só ocorre se os benefícios gerados pela divulgação das informações voluntárias (redução do custo de capital, aumento da liquidez das ações) sejam superiores aos seus custos (custo de elaboração e publicação das demonstrações, custos de propriedade). 
O argumento é que, se existem custos para se divulgar uma informação e o gestor decide não divulgá-la, os usuários podem pensar que (i) as informações são negativas ou (ii) as informações são positivas, mas não o suficiente para compensar os custos de propriedade (VERRECCHIA, 1983).

Nessa ótica, para interpretar a divulgação, ou não, de determinada informação, faz-se necessário conhecer os incentivos que os gestores possuem para se comportar de determinada maneira. A ideia por traz desse argumento é que, para interpretar as ações dos indivíduos, faz-se necessário antecipar seus incentivos e também o conjunto de ações alternativas que eles poderiam ter realizado, mas escolheram não fazer (DYE, 2001).

Caso se assuma que o objetivo do gestor é maximizar o valor da firma e que existem custos com o disclosure, parece existir um equilíbrio no qual a informação que aumenta o valor da empresa é divulgada de maneira voluntária e a informação que diminui não o é (VERRECCHIA, 2001). A noção central é que gestores estão interessados que suas empresas sejam julgadas favoravelmente. Assim, nota-se que se os incentivos dos gestores estão alinhados com os dos acionistas, ou seja, se eles procuram agir para maximizar o valor da firma, o disclosure voluntário de determinada informação só ocorrerá caso ele impacte positivamente a empresa, ou seja, sem a divulgação da informação o valor esperado da empresa é menor (DOBLER, 2005).

Contudo, nem sempre os gestores estão interessados em divulgar informações que maximizem o valor da empresa, visto que pode existir conflito de interesses entre esses e os acionistas da empresa (DYE, 2001; BAUMS, 2002), que, em muitos casos, pode levar à expropriação dos acionistas. Do mesmo modo, o gestor pode ter por objetivo aumentar os preços das ações em determinados momentos e diminuí-los em outros (FISHER; VERRECCHIA, 1998).

De acordo com Guay e Verrecchia (2007), o gestor agirá estrategicamente de acordo com seu próprio interesse, o que na maioria dos casos é a divulgação de informações boas acerca da empresa, e a não-divulgação de informações ruins. A ideia é que se o gestor acredita que a informação poderá ser utilizada contra ele, aumentam os incentivos para a não-divulgação (LAMBERT, 2001). O pressuposto econômico é que os gestores da empresa são racionais e que, quando permitido, ou seja, quando o disclosure não é obrigatório, não divulgarão informações que possam prejudicar a si mesmos ou à entidade (VERRECCHIA, 2001).

Assim, quando uma informação é boa, o gestor irá divulgá-la. Contudo, quando a informação é ruim, e não existe a obrigação de disclosure, não existirão, na maioria dos casos, benefícios na sua divulgação. De acordo com a Teoria da Disclosure Voluntário, a entidade tende a divulgar voluntariamente apenas informações positivas (DYE, 2001). 
Contudo, o usuário racional interpreta a informação não-divulgada como uma informação negativa, não favorável (VERRECCHIA, 2001). O raciocínio é que, se os investidores sabem que o gestor possui determinada informação e não a divulgou, eles racionalmente admitirão que a informação seja negativa. Sendo assim, poderiam assumir que o valor da empresa pode estar superestimado, o que os levaria a vender as ações da empresa e, consequentemente, a uma redução do valor de mercado da empresa (DYE, 1985).

Por exemplo, se uma empresa enfatiza repetidamente no seu Relatório de Administração que obteve uma redução de custos, mas não menciona nada sobre receitas, essas últimas provavelmente não foram boas, sendo que é possível fazer essa inferência mesmo antes de analisar a Demonstração do Resultado do Exercício (DYE, 2001).

Contudo, as empresas também poderão evidenciar informações negativas de maneira voluntária quando acreditarem que serão mais penalizadas pelos usuários externos, caso não as divulguem. Essa afirmação baseia-se no conceito de seleção adversa. O argumento é que, sem informação, as estimativas dos ativos da empresa (geralmente ações) passam a ser adversas, ou seja, a falta de informação leva os investidores a descontarem os ativos até o momento em que passa a ser interessante para a empresa divulgar a informação, mesmo sendo ela desfavorável (VERRECCHIA, 2001).

Finalmente, a Teoria do Disclosure Voluntário fornece o arcabouço conceitual para análise das condições em que as informações são voluntariamente divulgadas pelas firmas, em razão da interação estratégica com os agentes externos (acionistas, concorrentes, etc.) (DOBLER, 2005). De acordo com Hossain (2008), a Teoria do Disclosure Voluntário trata das circunstâncias que cercam a decisão de divulgar uma informação privada para o público. Conforme Verrecchia (2001), gestores geralmente possuem informações acerca da empresa cuja divulgação não é obrigatória. Logo, verificam-se em quais circunstâncias as empresas estariam dispostas a divulgá-la.

\section{METODOLOGIA}

Watts e Zimmerman (1986) argumentam que o objetivo da Teoria Contábil é explicar e prever a prática da Contabilidade, sendo que, dentro de uma abordagem positiva, a pesquisa envolve: (i) a formulação de hipóteses acerca de determinado comportamento dos agentes frente às decisões contábeis, (ii) utilização de um referencial teórico para o embasamento das hipóteses, (iii) teste empírico das hipóteses, e (iv) aceitação ou refutação de determinada explicação para o fenômeno observado.

Dentro dessa linha de pensamento, o presente trabalho pode ser classificado como uma pesquisa teórico-empírica de caráter explicativo, que tem como objetivo explicar o nível de disclosure voluntário das empresas. A partir de teorias existentes, formularam-se 
hipóteses que foram testadas empiricamente em uma amostra de empresas brasileiras. Por meio de uma análise quantitativa, buscou-se a confirmação ou a refutação das hipóteses a fim de explicar o disclosure voluntário das empresas brasileiras.

A descrição dos aspectos metodológicos do presente estudo está dividida em três partes: (i) amostra do estudo e do documento para análise, (ii) coleta e análise dos dados e (iii) hipóteses de pesquisa.

\subsection{Amostra do Estudo e do Documento para Análise}

A amostra não-probabilística totalizou 100 maiores empresas não-financeiras listadas na Bolsa de Valores de São Paulo (Bovespa). De acordo com Goulart, Lima e Gregório (2006), uma companhia é considerada aberta quando promove a colocação pública de valores mobiliários (ações, debêntures, bônus de subscrição, notas comerciais, etc.) em bolsas de valores ou no mercado de balcão.

Considerou-se apropriado excluir as empresas do setor financeiro por não possuírem características (ex: total das vendas, endividamento) que possam ser comparáveis a empresas não-financeiras. De acordo com Cooke (1989), considera-se apropriado excluir da amostra bancos, empresas de seguro e empresas financeiras em geral devido às particularidades de suas operações.

O disclosure voluntário das empresas foi analisado a partir das Demonstrações Financeiras Padronizadas (DFPs), do exercício findo em 2007, disponíveis no website da Bovespa. A escolha das demonstrações contábeis como fonte de análise do disclosure voluntário baseouse em duas justificativas: relevância para os usuários e comparabilidade entre empresas.

A relevância resulta da importância no processo de comunicação entre a empresa e seus stakeholders, já que as demonstrações contábeis são geralmente consideradas como o mais importante meio de comunicação das informações empresariais para os investidores (HAIL, 2003; BRAVO; ABAD; TROMBETTA, 2008). Já a comparabilidade decorre do fato de que todas as empresas de capital aberto são obrigadas a enviar as DFPs à Comissão de Valores Mobiliários (CVM). Do mesmo modo, devido a sua formalização estrutural, as demonstrações contábeis são de mais fácil comparação (HAIL, 2003).

\subsection{Coleta e Análise dos Dados}

O primeiro passo para a consecução do objetivo da pesquisa consistiu na avaliação do nível de disclosure voluntário das empresas selecionadas. Para isso, utilizou-se a técnica da análise de conteúdo. De acordo com Beretta e Bozzolan (2007), esse é o método mais utilizado nos estudos sobre disclosure, pois fornece credibilidade e inferência para análise de acordo com determinado contexto. Essa técnica tem como objetivo estudar de 
maneira rigorosa e sistemática a natureza das mensagens (KRIPPENDORFF, 1990).

Para a utilização da análise de conteúdo, faz-se necessária a definição de categorias e subcategorias para que o texto possa ser classificado, agrupado, por meio de características em comum das informações analisadas. Isto é, classificam-se as informações similares em categorias a fim de se realizarem melhores inferências (BARDIN, 1977). Assim, buscouse elaborar uma métrica para análise do disclosure voluntário das empresas.

Contudo, nota-se que uma das principais dificuldades nos estudos acerca do disclosure das empresas é a definição das possíveis informações (itens) que se espera encontrar nas demonstrações contábeis (COOKE, 1989; OWSHU-ANSAH, 1997). Segundo Wallace e Nasser (1995), não existe consenso sobre os itens que deveriam ser selecionados para a construção de uma métrica para avaliar o disclosure e essa decisão geralmente depende do foco da pesquisa.

Buscando-se reduzir a subjetividade na seleção das informações para a composição de uma métrica para avaliar o disclosure das empresas brasileiras, o presente trabalhou baseou-se em 13 estudos anteriores: Chow e Wong Boren (1987), Meek, Roberts, Gray (1995), Botosan (1997), Depoers (2000), Hail (2002), Lanzana (2004), Malacrida e Yamamoto (2006), Lima (2007), Alencar (2007), Francis, Nanda e Olsson (2008), Hossain (2008), Morris e Tronnes (2008), Orens e Lybaert (2008).

O Quadro 1 ilustra a métrica para a avaliação do nível de disclosure voluntário das empresas que atuam no Brasil a ser utilizado neste estudo, composta por seis categorias e 43 subcategorias: Ambiente de Negócios (8), Atividade Operacional (8), Aspectos Estratégicos (8), Informações Financeiras (7), Índices Financeiros (4) e Governança Corporativa (8).

\begin{tabular}{|l|l|}
\hline Categoria & Subcategoria \\
\hline \multirow{5}{*}{ Ambiente de Negócios } & Efeitos dos eventos econômicos na empresa (taxa de juros, inflação, crises, guerra) \\
\cline { 2 - 3 } & Discussão do setor em que a empresa atua \\
\cline { 2 - 3 } & Discussão da concorrência \\
\cline { 2 - 3 } & Relacionamento com fornecedores \\
\cline { 2 - 3 } & Satisfação dos clientes \\
\cline { 2 - 2 } & Market share \\
\cline { 2 - 2 } & Identificação dos riscos do negócio \\
\cline { 2 - 2 } & Exposição cambial \\
\hline \multirow{5}{*}{ Atividade Operacional } & Narrativa da história da empresa \\
\cline { 2 - 2 } & Estrutura organizacional \\
\cline { 2 - 2 } & Aspectos tecnológicos da atividade operacional \\
\cline { 2 - 2 } & Informações por segmento ou linha de negócio \\
\cline { 2 - 2 } & Utilização da capacidade produtiva \\
\cline { 2 - 2 } & Indicadores de eficiência \\
\hline & Quantidades produzidas e/ou serviços prestados \\
\cline { 2 - 2 } & Unidades vendidas \\
\hline
\end{tabular}




\begin{tabular}{|c|c|}
\hline \multirow{8}{*}{ Aspectos Estratégicos } & Objetivos, planos e metas futuras da empresa \\
\hline & Perspectiva de novos investimentos \\
\hline & Principais mercados de atuação \\
\hline & Perspectivas de novos mercados que a empresa pretende atuar \\
\hline & Política de reinvestimento dos lucros \\
\hline & Pesquisa e desenvolvimento \\
\hline & Discussão da qualidade dos produtos e serviços \\
\hline & Preço dos produtos e serviços da empresa \\
\hline \multirow{7}{*}{$\begin{array}{l}\text { Informações } \\
\text { Financeiras }\end{array}$} & Correção monetária \\
\hline & Demonstração do Fluxo de Caixa (DFC) \\
\hline & Informações contábeis em US GAAP ou IFRS \\
\hline & Informações detalhada sobre os custos dos produtos, serviços (CMV, CPV) \\
\hline & Preço ou valorização das ações por tipo (ON, PN) \\
\hline & Valor de mercado \\
\hline & Projeções (fluxo de caixa, vendas, lucros) \\
\hline \multirow{4}{*}{ Índices Financeiros } & Indicadores de rentabilidade (ROE, ROA) \\
\hline & Indicadores de liquidez (liquidez corrente, liquidez seca) \\
\hline & Indicadores de endividamento (PL - Passivo, PC-PELP) \\
\hline & EBITDA \\
\hline \multirow{8}{*}{$\begin{array}{l}\text { Governança } \\
\text { Corporativa }\end{array}$} & Principais práticas de governança corporativa \\
\hline & Composição do conselho fiscal \\
\hline & Composição do conselho de administração \\
\hline & Identificação dos principais administradores \\
\hline & Remuneração dos administradores \\
\hline & Remuneração dos auditores \\
\hline & Principais acionistas \\
\hline & Relacionamento com os investidores \\
\hline
\end{tabular}

\section{Quadro 1 - Métrica para avaliação do disclosure voluntário}

Optou-se por avaliar as informações divulgadas de forma binária, ou seja, caso a empresa tenha divulgado determinada informação receberá nota 1, caso contrário, nota 0 . Assim, trata-se de um ranking quantitativo que verifica a existência, ou não, de determinada informação (KHANNA; PALEPU; SRINIVASAN, 2004).

A ideia é que pesos iguais refletem a percepção de todos os usuários em conjunto, sem privilegiar determinado grupo (WALLACE; NASER, 1995; COOKE, 1989). Do mesmo modo, resultados evidenciam que a atribuição de pesos e a não-atribuição apresentam resultados similares quando se utiliza uma métrica com um grande número de itens (BEATTIE; McINNES; FEARNLEY, 2004). Com base nesse critério, o nível de disclosure voluntário é dado pelo número de categorias evidenciadas pela empresa, dividido pelo número total de subcategorias (43). Por exemplo, a Usiminas atingiu um nível de disclosure voluntário de 69,77\% (30/43).

Ressalta-se que foi realizado o teste Alpha de Cronbach que, de acordo com Martins e Theóphilo (2007), visa mensurar a confiabilidade do instrumento de pesquisa. Segundo 
Botosan (1997), esse teste avalia a consistência interna da métrica e serve para testar as várias categorias de um índice de disclosure. Os resultados confirmaram a validade interna da métrica de disclosure voluntário utilizada nesta pesquisa na medida em que o Alpha de Cronbach resultou em 0,916 (ou 91,60\%).

\subsection{Hipóteses de Pesquisa}

A fim de verificar quais características das empresas explicam a divulgação voluntária de informações, foram formuladas nove hipóteses: (i) auditoria, (ii) nível de rentabilidade, (iii) internacionalização, (iv) tamanho, (v) governança corporativa, (vi) nível de endividamento, (vii) concentração do controle acionário, (viii) emissão de ações, e (ix) setor. A seguir, apresenta-se a descrição das hipóteses juntamente com as justificativas teóricas.

- H1: Empresas auditadas por 'Big Four' possuem maior nível de disclosure voluntário do que empresas auditadas por 'outras empresas de auditoria'.

Grandes empresas de auditoria influenciam a qualidade do disclosure das companhias fazendo com que as empresas por elas auditadas divulguem mais informações (ARCHAMBAULT; ARCHAMBAULT, 2003). Logo, empresas de auditoria pertencentes ao seleto grupo das 'Big Four' (KPMG, PricewaterhouseCoopers, Deloitte Touche Tohmatsu e Ernst\&Young) tendem a não se associar a clientes com um nível baixo de evidenciação (AHMAD; HASSAN; MOHAMMAD, 2003). Afinal, como são empresas internacionais de grande porte, também possuem maior risco de litígio que empresas menores.

Nota-se que empresas que escolhem auditores dentro do grupo das Big Four tendem a possuir um disclosure melhor, pois geralmente esses profissionais são mais exigentes com relação à divulgação de acordo com as normas contábeis (FROST; GORDON; POWNALL, 2008). Do mesmo modo, as companhias tendem a escolher seus auditores como parte de sua estratégia geral de disclosure (PATTON; ZELENKA, 1997), sendo que a escolha de uma empresa 'Big Four' visa fornecer mais credibilidade às demonstrações contábeis (HOSSAIN, 2008).

Para operacionalizar a hipótese 'auditoria', utilizou-se uma variável dicotômica, com valor igual a 1, caso a empresa tenha sido auditada no exercício findo em 2007 por uma empresa pertencente ao grupo das 'Big Four'; e valor igual a 0, caso a empresa tenha sido auditada por uma empresa de auditoria não-pertencente a esse grupo.

- H2: Empresas com maior nível de rentabilidade possuem maior nível de disclosure voluntário do que as empresas com menor nível de rentabilidade.

Ser avaliado como um "abacaxi" representa um custo para a empresa (AKERLOF, 1970). Ora, para amenizar esse problema, gestores de empresas de melhor "qualidade" teriam incentivos para realizar ações para demonstrar que são melhores, como, por 
exemplo, a divulgação voluntária de informações. A relação positiva entre o disclosure e a performance da empresa é subsidiada pelo desenvolvimento de modelos analíticos de disclosure voluntário que consideram o problema da assimetria informacional (LANG; LUNDHOLM, 1993), sendo que empresas mais rentáveis tendem a divulgar mais informações para se diferenciar de empresas menos rentáveis e reduzir o risco de seleção adversa (AKERLOF, 1970).

A proxy utilizada para operacionalizar a hipótese 'rentabilidade' foi o Retorno sobre Patrimônio Liquido (ROE) de 2007, que foi computado dividindo o Lucro Líquido de 2007 pelo saldo médio do Patrimônio Líquido de 2007.

- H3: Empresas que possuem títulos e valores mobiliários negociados na Bolsa de Nova lorque (NYSE) possuem maior nível de disclosure voluntário do que empresas que negociam apenas na Bolsa de Valores de São Paulo.

Nota-se que empresas que possuem títulos e valores mobiliários negociados em mercados internacionais possuem maior pressão do mercado para divulgar informações quando comparadas com empresas listadas apenas nas bolsas de seus respectivos países (MEEK; ROBERTS; GRAY, 1995). De acordo com Archambault e Archambault (2003), a política de disclosure de uma empresa tende a ser influenciada pelo mercado de capitais no qual seus títulos são negociados.

A operacionalização dessa hipótese se deu por meio da utilização de uma variável dummy, como valor igual a 1, caso a empresa emitisse American Depositary Receipts $(A D R)$ nos Níveis II e III; e 0, caso a empresa não emitisse esses títulos.

A justificativa para operacionalização dessa hipótese deve-se ao fato de que as empresas que listam seus títulos no mercado norte-americano, por meio da emissão de ADR Nível I e Regra 144-A, não são obrigadas a atender às normas contábeis norte-americanas e tampouco às exigências completas da SEC (LIMA; OZAWA; GOULART, 2006). Sendo assim, a hipótese acima assume que apenas as empresas obrigadas a elaborar demonstrações contábeis em US GAAP e a atender às exigências da SEC, divulgam, em tese, mais informações de maneira voluntária no Brasil.

- H4: Empresas maiores possuem maior nível de disclosure voluntário do que empresas menores.

De acordo com Diamond (1985), e Diamond e Verrechia (1991), espera-se que empresas maiores possuam um disclosure de melhor qualidade, pois seus benefícios tendem a ser maiores. A lógica por traz dessa afirmação é a de que a melhoria no disclosure tende a aumentar a penetração no mercado e, consequentemente, atrair investidores maiores, que geralmente estão associados a empresas de grande porte (GHOSE, 2006). Nessa linha de pensamento, gestores de grandes companhias tendem a acreditar mais fortemente nos benefícios do disclosure do que gestores de pequenas companhias (HOSSAIN, 2008). 
Percebe-se também que empresas maiores possuem maiores custos políticos devido à sua visibilidade perante a sociedade, o que pode atrair a atenção do governo e do mercado como um todo. Essa hipótese é conhecida como political cost hipothesis (WATTS; ZIMMERMAN, 1986). A ideia é que grandes empresas sofrem pressões políticas, pois seu impacto na economia é considerável na medida em que produzem uma grande quantidade de bens e serviços, geram muitos empregos etc. (WALLACE; NASER, 1995). Nesse sentido, são mais 'visíveis' aos olhos públicos e tendem a evidenciar mais informações para aumentar sua reputação corporativa (FIRTH, 1979) e reduzir os custos políticos (WATTS; ZIMMERMAN, 1986).

Como proxy para a hipótese 'tamanho' da empresa, utilizou-se o Logaritmo Natural (Ln) da Receita Bruta no ano de 2007.

- H5: Empresas que aderem aos Níveis de Governança Corporativa da Bovespa possuem maior nível de disclosure voluntário do que empresas que não aderem a esses níveis.

De acordo com a hipótese do vínculo (bonding hypothesis), empresas presentes em países com fracos arcabouços institucionais, caracterizados pela baixa proteção aos acionistas, como o Brasil, possuem dificuldade de se autofinanciar, o que, consequentemente, as leva a buscar mecanismos adicionais para demonstrar aos investidores que são confiáveis (LEUZ, 2006), como, por exemplo, a adoção de melhores práticas de governança corporativa.

Assim, para as empresas brasileiras de capital aberto uma opção seria aderir aos Níveis de Governança Corporativa (Nível 1, Nível 2 e Novo Mercado) da Bovespa. Nota-se que essa adesão também tende a influenciar o disclosure das empresas. Por exemplo, no Nível 2 e no Novo Mercado, exige-se a disponibilização do Balanço da Empresa em US GAAP ou IFRS (CARVALHO, 2002). Na prática, contudo, nota-se que as empresas optam por divulgar apenas a reconciliação do Lucro e do Patrimônio Líquido, de US GAAP ou IFRS para BR GAAP.

Utilizou-se também uma variável dicotômica, com valor igual a 1, caso empresa tivesse aderido aos Níveis de Governança Corporativa da Bovespa até o final de 2007; e 0; caso a empresa não tivesse aderido a esses níveis.

- H6: Empresas com maiores níveis de endividamento possuem maior nível de disclosure voluntário que as empresas com menor nível de endividamento.

Quanto maior a proporção de dívida na estrutura de capital de uma empresa, maior os custos de agência, pois possibilita uma maior transferência de riqueza dos credores para os acionistas (DEPOERS, 2000). Assim, de acordo com a Teoria da Agência, gestores de empresas com maior nível de endividamento tendem a divulgar voluntariamente mais 
informações para satisfazer aos credores e remover as suspeitas sobre a transferência de riqueza para os acionistas (JENSEN; MECKLING, 1976).

Do mesmo modo, empresas com maiores níveis de endividamento são monitoradas de maneira mais rigorosa pelas instituições financeiras, sendo sujeitas a divulgar mais informações que empresas com menores níveis de endividamento (AHMED; NICHOLLS, 1994).

A operacionalização dessa variável foi realizada por meio da divisão do Passivo Exigível pelo Ativo Total das empresas, saldo final, no ano de 2007.

- H7: Empresas com o controle acionário mais diluído possuem maior nível de disclosure voluntário do que empresas com controle acionário mais concentrado.

Quanto mais disperso for o controle de uma empresa, maior a separação entre propriedade e controle e, consequentemente, maiores os conflitos de agência entre os controladores e os usuários externos da empresa (DEPOERS, 2000), sendo que a extensão desses conflitos influencia o nível de disclosure voluntário (CHOW; WONG-BOREN, 1987). A premissa é que investidores que possuem uma porcentagem significante das ações podem obter informações diretamente com a empresa (ARCHAMBAULT; ARCHAMBAULT, 2003), pois geralmente fazem parte da gestão, do conselho de administração, possuindo acesso privilegiado às informações (LEUZ, 2006).

Assim, espera-se que empresas com o controle acionário mais diluído divulguem mais informações do que aquelas controladas por grandes acionistas (RAFFOUNIER, 1995), já que o disclosure torna-se mais relevante para resolver os problemas de assimetria informacional (ALENCAR, 2007).

Para operacionalizar a hipótese 'controle acionário', utilizou-se uma variável dicotômica, com valor igual a 1 , caso o principal acionista da empresa detivesse menos de $50 \%$ das ações com direito ao voto na empresa; e 0, caso o principal acionista da empresa detivesse mais de $50 \%$ das ações com direito ao voto na empresa.

- H8: Empresas que emitiram ações no ano de 2008 possuem maior nível de disclosure voluntário do que empresas que não emitiram ações nesse período.

De maneira geral, se a empresa conseguir reduzir a assimetria informacional no período de emissão de ações, isso acarretará em um menor custo de capital (LANG; LUNDHOLM, 2000). Assim, mesmo sem a presença de uma lei que obrigue a divulgação de informações aos investidores, empresas estariam dispostas a divulgar informações no momento da emissão de títulos (BAUMS, 2002).

A teoria é que quando a empresa emite ações, ela corre o risco de ser subavaliada, principalmente quando existem informações favoráveis que a empresa possui que não são divulgadas aos investidores. A subavaliação no momento da oferta pública (underpricing) 
representa a diferença entre o preço de oferta das ações, o qual é determinado pela empresa, e o preço de fechamento da ação no primeiro dia (SCHRAND; VERRECCHIA, 2005).

Para operacionalizar essa hipótese, utilizou-se uma variável dummy, com valor igual a 1, caso a empresa tivesse emitido ações no ano de 2008; e 0; caso a empresa não tivesse emitido ações nesse período.

- H9: Empresas do setor elétrico possuem maior nível de disclosure voluntário do que empresas de outros setores.

É mister ressaltar que as regulamentações específicas de alguns setores também fazem parte do que se considera "práticas contábeis adotadas no Brasil". Isso ocorre, por exemplo, no setor elétrico. Nesse setor, existe regulamentação específica, Aneel 444/01, emitida pela Agência Nacional de Energia Elétrica (Aneel), que institui o Manual de Contabilidade do Serviço Público de Energia Elétrica. De acordo com essa legislação, as empresas são estimuladas, por exemplo, a publicar a Demonstração do Fluxo de Caixa, Demonstração do Valor Adicionado e o Balanço Social.

A existência dessa regulação específica e também do enforcement do órgão regulador tem resultado em um alto nível de disclosure das empresas do setor elétrico. Por exemplo, das companhias (abertas e fechadas) premiadas pelo Troféu Transparência 2008, concedido para as empresas com demonstrações contábeis mais transparentes no ano de 2007, quatro são do setor elétrico: Companhia Energética de Minas Gerais (Cemig), Companhia Energética de São Paulo (Cesp), Centrais Elétricas do Norte do Brasil S/A e Energisa Borborema. Nesse sentido, considerou-se apropriada a utilização de uma variável dummy para controlar o efeito do setor elétrico na análise dos determinantes do disclosure voluntário das empresas.

\section{RESULTADOS}

Com o objetivo de responder ao problema de pesquisa, utilizou-se um modelo de regressão linear múltipla, no qual o nível de disclosure voluntário é a variável dependente ou explicada, e as nove hipóteses de pesquisa são as variáveis independentes ou explicativas. A Tabela 1 apresenta o modelo de disclosure voluntário inicial.

Tabela 1 - Modelo de Disclosure Voluntário Inicial

\begin{tabular}{|l|c|c|c|c|c|c|}
\hline Model & $\boldsymbol{\Sigma}$ Squares & df & $\begin{array}{c}\text { Mean } \\
\text { Square }\end{array}$ & F & Sig. & R2 \\
\hline Regression & 1420,062 & 10 & 142,006 & 5,901 &, $000(a)$ &, 399 \\
\hline Residual & 2141,648 & 89 & 24,063 & & & Adjusted R2 \\
\hline Total & 3561,710 & 99 & & & &, 331 \\
\hline
\end{tabular}




\section{repec}

\begin{tabular}{|l|c|c|c|c|c|c|}
\hline Model & B & $\begin{array}{c}\text { Std. } \\
\text { Error }\end{array}$ & Standard B & $\mathbf{t}$ & Sig. & VIF \\
\hline (Constant) & $-6,827$ & 8,638 & &,- 790 &, 431 & \\
\hline Setor & 3,972 & 1,275 &, 276 & 3,115 &, 002 & 1,159 \\
\hline Endividamento &,- 034 &, 025 &,- 116 & $-1,333$ &, 186 & 1,128 \\
\hline Internacionalização & 5,056 & 1,647 &, 303 & 3,069 &, 003 & 1,438 \\
\hline Tamanho & 1,483 &, 562 &, 253 & 2,639 &, 010 & 1,365 \\
\hline Rentabilidade &, 012 &, 011 &, 093 & 1,052 &, 295 & 1,155 \\
\hline Governança & 1,480 & 1,150 &, 123 & 1,286 &, 202 & 1,355 \\
\hline Auditoria & 1,653 & 1,428 &, 102 & 1,158 &, 250 & 1,139 \\
\hline Controle Acionário &, 396 & 1,315 &, 027 &, 301 &, 764 & 1,192 \\
\hline Emissão de Ações & 2,868 & 2,712 &, 094 & 1,057 &, 293 & 1,174 \\
\hline
\end{tabular}

Constata-se que o modelo como um todo é válido, conforme o teste $\mathrm{F}$, e possui um poder explicativo de cerca de $33 \%$, de acordo com o $\mathrm{R}^{2}$ ajustado. Nota-se também que nesse modelo inicial apenas três variáveis podem ser consideradas estatisticamente significativas para um nível de significância de 5\%: Setor, Internacionalização e Tamanho.

Contudo, buscou-se verificar se algumas das seis variáveis consideradas não-significativas a priori poderiam ser incluídas no modelo, quando consideradas separadamente. Para isso, utilizou-se o método Stepwise de regressão múltipla, que seleciona as variáveis com base na sua relevância estatística para o modelo. Admitindo um nível de confiança de 95\%, foi possível incluir a hipótese 'governança corporativa' no modelo. Assim, realizou-se novamente o teste de regressão múltipla apenas com as variáveis consideradas significativas, conforme tabela a seguir.

Tabela 2 - Modelo de Disclosure Voluntário Final

\begin{tabular}{|l|c|c|c|c|c|c|}
\hline Model & $\boldsymbol{\Sigma}$ Squares & df & $\begin{array}{c}\text { Mean } \\
\text { Square }\end{array}$ & $\mathbf{F}$ & Sig. & R2 \\
\hline Regression & 1236,381 & 4 & 309,095 & 12,628 &, $000(\mathrm{a})$ &, 347 \\
\hline Residual & 2325,329 & 95 & 24,477 & & & Adjusted R2 \\
\hline Total & 3561,710 & 99 & & & &, 320 \\
\hline Model & $\mathbf{B}$ & Std. Error & Standard B & $\mathbf{t}$ & Sig. & VIF \\
\hline (Constant) & $-11,126$ & 8,236 & & $-1,105$ &, 272 & \\
\hline Setor & 3,859 & 1,223 &, 268 & 3,445 &, 001 & 1,049 \\
\hline Internacionalização & 4,829 & 1,646 &, 289 & 2,804 &, 006 & 1,412 \\
\hline Tamanho & 1,760 &, 555 &, 301 & 2,613 &, 010 & 1,308 \\
\hline Governança & 2,444 & 1,053 &, 203 & 2,163 &, 033 & 1,117 \\
\hline
\end{tabular}

Percebe-se que o modelo final possui poder explicativo de $32 \%$ e possui quatro variáveis estatisticamente significantes: Setor, Internacionalização, Tamanho e Governança 


\section{repec}

Corporativa. Nota-se também a existência de uma relação positiva entre essas variáveis independentes e a variável dependente disclosure econômico, que pode ser visualizada através do sinal dos Betas.

Ressalta-se a ausência de multicolinearidade entre as variáveis independentes no modelo, já que o indicador VIF está abaixo de 1,5. Isso também foi confirmado por meio da matriz de correlação entre as variáveis independentes. Do mesmo modo, o problema da heteroscedasticidade foi identificado e corrigido por intermédio da matriz de covariância de White.

Com base nas análises, é possível afirmar que empresas maiores, pertencentes ao setor elétrico, que possuem títulos e valores mobiliários negociados na Bolsa de Nova lorque nos níveis II e III e que aderem aos níveis diferenciados de governança da Bolsa de São Paulo, possuem, em média, um maior nível de disclosure voluntário de caráter econômico.

De certa forma, o fato de o tamanho da empresa ter sido significativo confirma a political cost hipothesis de Wattz e Zimmerman (1986), na medida em que grandes empresas possuem pressão política devido à sua reputação e ao seu impacto na economia. Contudo, é mister ressaltar que grandes empresas também possuem um departamento de contabilidade maior, mais recursos para preparar e divulgar suas demonstrações contábeis, sendo que isso obviamente também influencia o nível de disclosure da empresa.

Do mesmo modo, a significância estatística das hipóteses "governança" e "internacionalização" pode ser interpretada à luz da bonding hypothesis, já que algumas empresas brasileiras listam suas ações em níveis diferenciados de governança e no mercado internacional se comprometendo a maior transparência e a melhores práticas de disclosure. Finalmente, a regulação setorial também se mostrou significativa já que as empresas do setor elétrico possuem em média um nível de disclosure superior às empresas de outros setores.

\section{CONSIDERAÇÕES FINAIS}

O presente estudo teve por objetivo explicar o nível de disclosure voluntário das companhias abertas no Brasil, fundamentando-se na Teoria do Disclosure Voluntário de Verrecchia (2001). A análise do disclosure voluntário foi realizada a partir das Demonstrações Financeiras Padronizadas do exercício findo em 2007, por meio da análise de conteúdo, sendo que a amostra foi composta pelas 100 maiores companhias abertas não-financeiras.

Como contribuições do trabalho destacam-se:

- A partir de 13 estudos anteriores, elaborou-se uma métrica para avaliar o nível de disclosure voluntário da empresas, composta por seis categorias e 43 subcategorias: ambiente de negócios (8), atividade operacional (8), aspectos estratégicos (8), informações financeiras (7), índices financeiros (4) e governança corporativa (8). A consistência interna dessa métrica foi comprovada já que o Alpha de Cronbach foi de 0,916 ou $91,60 \%$. 
- Com base nas teorias existentes, foram formuladas nove hipóteses (auditoria, rentabilidade, internacionalização, tamanho, governança corporativa, endividamento, controle acionário, emissão de ações e setor), que, posteriormente, foram testadas através de um modelo de análise de regressão múltipla.

As principais constatações da pesquisa foram:

- O nível de disclosure voluntário das empresas pode ser explicado fundamentalmente pela hipótese do vínculo (bonding hypothesis), no que diz respeito às hipóteses "governança corporativa" e "internacionalização". Esses resultados corroboram estudos anteriores na Suécia (COOKE, 1989), no Japão (COOKE, 1992) e na Malásia (HOSSAIN; TAN; ADAMS, 1994).

- A hipótese "tamanho" também está positivamente associada com o nível de disclosure voluntário das empresas, corroborando a hipótese dos custos políticos (political costs hypothesis) e pesquisas anteriores no México (CHOW; WONGBOREN, 1987), na Suécia (COOKE, 1989), no Japão (COOKE, 1992), na Malásia (HOSSAIN; TAN; ADAMS, 1994), em Hong Kong (WALLACE; NASSER, 1995), na Suíça (RAFOUNIER, 1995), ma República Checa (PATTON; ZELENKA, 1997) e na França (DEPOERS, 2000).

- A regulação setorial, mais especificamente no que diz respeito à Agência Nacional de Energia Elétrica, parece influenciar positivamente o nível de disclosure, conforme resultado da hipótese "setor".

É mister ressaltar algumas limitações da pesquisa. A amostra do estudo, composta pelas 100 maiores empresas não-financeiras, é intencional e não-probabilística. Analisaramse apenas as demonstrações contábeis do exercício findo de 2007. Nesse sentido, os resultados não devem ser generalizados para outras empresas e outros períodos de tempo.

\section{REFERÊNCIAS}

AHMAD, Zauwiyah; HASSAN, Salleh; MOHAMMAD, Junaini. Determinants of environmental reporting in Malaysia. International Journal of Business Studies, v. 11, p. 69-90, 2003.

AHMED, Kamran; NICHOLLS, Des. The impact of non-financial company characteristics on mandatory compliance in developing countries: The case of Bangladesh. International Journal of Accounting, v. 29, p. 60-66, 1994.

AKERLOF, George. The market for "lemons": quality uncertainty and the market mechanism. Quarterly Journal of Economics, v. 84, p. 488-500, 1970. 
ALENCAR, Roberta. Nível de disclosure e custo de capital próprio no mercado brasileiro. Tese (Doutorado em Controladoria e Contabilidade) - Faculdade de Economia, Administração e Contabilidade, Universidade de São Paulo, São Paulo. 2007.

ARCHAMBAULT, Jeffrey; ARCHAMBAULT, Marie. A multinational test of determinants of corporate disclosure. International Journal of Accounting, v. 38, p. 173-194, 2003.

BARDIN, Laurence. Análise de conteúdo. Lisboa: Edições 70, 1977.

BAUMS, Theodor. Changing patterns of corporate disclosure in continental Europe: The example of Germany. European Corporate Governance Institute (EGCl) - Law Working Paper. Social Science Research Network. Disponível em: <www.ssrn.com>. Outubro, 2002. Acesso em 11 de Setembro de 2008.

BEATTIE, Vivien; McINNES, Bill; FEARNLEY, Stella. A methodology for analysing and evaluating narratives in annual reports: A comprenhensive descriptive profile and metrics for disclosure quality attributes. Accouting Forum, v. 28, p. 205-236, 2004.

BERETTA, Sérgio; BOZZOLAN, Saverio. Quality versus quantity: The case of forwardlooking disclosure. Journal of Accounting, Auditing and Finance, Forthcoming, 2008. Social Science Research Network. Disponível em: <www.ssrn.com>. Janeiro, 2007. Acesso em 11 de Setembro de 2008.

BOTOSAN, Christine. Disclosure level and cost of equity capital. The Accounting Review, v. 72, p. 323-349, 1997.

BRAVO, Francisco; ABAD, Cristina; TROMBETTA, Marco. Methodological and empirical analysis of problems in the measurement of voluntary disclosure. In: European Accounting Association Annual Congress, 31, 2008, Rotterdam.

CARVALHO, Antônio Gledson de. Governança corporativa no Brasil em perspectiva. Revista de Administração, v. 37, p. 19-32, 2002.

CHOW, Chee; WONG-BOREN, Adrian. Voluntarily disclosure by Mexican companies. The Accounting Review, v. 62, p. 533-541, 1987.

COOKE, Terence E. Disclosure in the corporate annual reports of Swedish companies. Accounting and Business Research, v. 19, p. 113-124, 1989. 
COOKE, Terence E. The impact of size, stock market listing and industry type on disclosure in the annual reports of Japanese listed corporations. Accounting and Business Research, v. 22, p. 229-237, 1992.

CUNHA, Jacqueline; RIBEIRO, Maisa. Divulgação voluntária de informações de natureza social: um estudo nas empresas brasileiras. In: ENANPAD, 30., 2006, Salvador. Anais... Brasília: ANPAD, 2006. CD-ROM.

DEPOERS, Florence. A cost benefit study of voluntarily disclosure: some empirical evidence from French listed companies. European Accounting Review, v. 9, p. 245-263, 2000.

DIAMOND, Douglas. Optimal realease of informations by firms. Journal of Finance, v. 40, p. 1071-1094, 1985.

DIAMOND, Douglas; VERRECCHIA, Robert. Disclosure, liquidity and the cost of capital. Journal of Finance, v. 46, p. 1325-1360, 1991.

DOBLER, Michael. How informative is risk reporting? A review of disclosure models. Munich Business Research Working Paper. Social Science Research Network. Disponível em: <www.ssrn.com>. Janeiro, 2005. Acesso em 22 de Agosto de 2008.

DYE, Ronald. Disclosure of nonproprietary information. Journal of Accounting Research, v. 23, p. 123-145, 1985.

DYE, Ronald. An evaluation of 'essays on disclosure' and the disclosure literature in accounting. Journal of Accounting and Economics, v. 32, p. 181-235, 2001.

FIRTH, Michael. The impact of size, stock market listing, and auditors on voluntary disclosure in corporate annual reports. Accounting and Business Research, v. 9, p. 273-280, 1979.

FISHER, Paul; VERRECCHIA, Robert. Reporting bias. Social Science Research Network. Disponível em: <www.ssrn.com>. Julho, 1998. Acesso em 15 de Setembro de 2008.

FRANCIS, Jere; KHURANA, Inder; PEREIRA, Raynolde. Disclosure incentives and effects on cost of capital around the world. The Accounting Review, v. 80, p. 1125-1162, 2005.

FRANCIS, Jennifer; NANDA, Dhananjay; OLSON, Per. Voluntarily disclosure, information quality, and costs of capital. Journal of Accounting Research, v. 46, p. 53-99, 2008. 
FROST, Carol; GORDON, Elizabeth; POWNALL, Grace. Financial reporting and disclosure quality, and emerging market companies' acess to capital in global markets. Social Science Research Network. Disponível em: <www.ssrn.com>. Abril, 2008. Acesso em 22 de Agosto de 2008.

GHOSE, Anindya. Information disclosure and regulatory compliance: Economic issues and research directions. Social Science Research Network. Disponível em: <www.ssrn. com>. Julho, 2006. Disponível em 22 de Agosto de 2008.

GOULART, André; LIMA, Gerlando; GREGÓRIO, Jaime. Mercado de renda variável. In: LIMA, Iran; LIMA, Gerlando; PIMENTEL, René. Curso de mercado financeiro: Tópicos especiais. São Paulo: Editora Atlas, 2006.

GUAY, Wayne; VERRECCHIA, Robert. Conservative disclosure. Social Science Research Network. Disponível em: <www.ssrn.com>. Junho, 2007. Acesso em 22 de Agosto de 2008.

HAIL, Luizi. The impact of voluntarily corporate disclosure on the ex ante cost of capital for Swiss firms. European Accounting Review, v. 11, p. 741-743, 2003.

HEALY, Paul; HUNTTON, Amy; PALEPU, Krishna. Stock performance and intermediation changes surrounding sustained increases in disclosure. Contemporary Accounting Research, v. 16, p. 485-520, 1999.

HOSSAIN, Mahmud; TAN, Lin; ADAMS, Mike. Voluntarily disclosure in an emerging capital market: Some empirical evidence from companies listed in the Kuala Lumpur Stock Exchange. The International Journal of Accounting, v. 29, p. 334-351, 1994.

HOSSAIN, Mohammed. The extent of disclosure in annual reports of banking companies: The case of India. American Accounting Association Annual Meeting, 2008, Anaheim.

KHANNA, Tarun; PALEPU, Krishna; SRINIVASAN, Suraj. Disclosure practices of foreign companies interacting with U.S. markets. Journal of Accounting Research, v. 42 p. 475-508, 2004.

JENSEN, Michael; MECKLING, William. Theory of firm: Managerial behavior, agency costs and ownership structure. Journal of Financial Economics, v. 3, p. 305-360, 1976. 


\section{repec}

KRIPPENDORFF, Klaus. Metodología de análisis de contenido: teoría y práctica. BarceIona: Paidós Comunicación, 1990.

LAMBERT, Richard. Contracting theory and accounting. Journal of Accounting and Economics, v. 32, p. 3-87, 2001.

LANG, Mark; LUNDHOLM, Russell. Cross-sectional determinants of analyst rating of corporate disclosures. Journal of Accounting Research, v. 31, p. 246-271, 1993.

LANG, Mark; LUNDHOLM, Russell. Voluntary disclosure and equity offerings: Reducing information asymmetry or hyping the stock. Contemporary Accounting Research, v. 17, p. $623-662,2000$.

LANZANA, Ana. Relação entre o disclosure e governança corporativa das empresas brasileiras. Dissertação (Mestrado em Administração) - Faculdade de Economia, Administração e Contabilidade, Universidade de São Paulo, São Paulo, 2004.

LEUZ, Christian; VERRECCHIA, Robert. The economic consequences of increased disclosure. Journal of Accounting Research, v. 38, p. 91-124, 2000.

LEUZ, Christian. Cross listing, bonding and firms reporting incentives: A discussion of Lang, Raedy and Wilson. Journal of Accounting and Economics, v. 42, p. 285-299, 2006.

LEUZ, Christian; WYSOCKI, Peter. Economic consequences of financial reporting and disclosure regulation: A review and suggestions for future research. Social Science Research Network. Disponível em: <www.ssrn.com>. Março, 2008. Acesso em 22 de Agosto de 2008.

LEVITT, Arthur. The importance of high quality accounting standards. Accounting Horizons, v. 12, p. 79-82, 1998.

LIMA, Gerlando; OZAWA, Celina; GOULART, André. Underwriting, ações, ADR e BDR. In: LIMA, Iran; LIMA, Gerlando; PIMENTEL, René. Curso de mercado financeiro: Tópicos especiais. São Paulo: Editora Atlas, 2006.

LIMA, Gerlando. Utilização da Teoria da Divulgação para avaliação da relação do nível de disclosure com o custo da dívida das empresas brasileira. 118 p. Tese (Doutorado em Controladoria e Contabilidade) - Faculdade de Economia, Administração e Contabilidade, Universidade de São Paulo, São Paulo, 2007. 
MALACRIDA, Mara; YAMAMOTO, Marina. Governança corporativa: Nível de evidenciação das informações e sua relação com a volatilidade das ações do IBOVESPA. Revista Contabilidade e Finanças, Edição Comemorativa, p. 65-79, 2006.

MARTINS, Gilberto; THEOPHILO, Carlos. Metodologia da investigação científica para ciências sociais aplicadas. São Paulo: Editora Atlas, 2007.

MEEK, Gary; ROBERTS, Clare; GRAY, Sid. Factors influencing voluntarily annual report disclosure by U.S., U.K., and continental European multinational corporations. Journal of International Business Studies, v. 26, p. 555-572, 1995.

MORRIS, Richard D., TRONNES, Per Christen. The determinants of voluntary strategy disclosure: An international comparison. American Accounting Association Annual Meeting, 2008, Anaheim.

ORENS, Raf; LYBAERT, Nadine. Analysts' earnings forecasts and non-financial disclosures. In: European Accounting Association Annual Congress, 31, 2008, Rotterdam.

OWUSU-ANSAH, Stephen. The determinants of voluntary financial disclosure by Swiss listed companies: A comment. The European Accounting Review, v. 6, p. 487-492, 1997.

PATTON, James; ZELENKA, Ivan. An empirical analysis of the determination of the extent disclosure in annual reports of joint stock companies in the Czech Republic. The European Accounting Review, v. 6, p. 605-626, 1997.

RAFFOURNIER, Bernard. The determinants of voluntary disclosure by Swiss Listed Companies. European Accounting Review, v. 4, p. 261-280, 1995.

SCHRAND, Catherine; VERRECCHIA, Robert. Information disclosure and adverse selection explanation for IPO underpricing. Social Science Research Network. Disponível em: <www.ssrn.com>. Outubro, 2005. Acesso em 11 de Setembro de 2008.

SENGUPTA, Partha. Corporate disclosure quality and the cost of debt. The Accounting Review, v. 73, p. 459-474, 1998.

SHIN, Hyun. Disclosures and asset return. Econometrica, v. 71, p. 105-133, 2003. 
VERRECCHIA, Robert. Discretionary disclosure. Journal of Accounting and Economics, v. 5, p. $179-194,1983$.

VERRECCHIA, Robert. Essays on disclosure. Journal of Accounting and Economics, v. 22, p. 97-180, 2001.

WALLACE, Olusegun; NASER, Kamal. Firm specific determinants of the comprehensiveness of mandatory disclosure in the corporate annual reports of firms listed on the stock exchange of Hong Kong. Journal of Accounting and Public Policy, v. 14, p. 311-368, 1995.

WATTS, Ross; ZIMMERMAN, Jerold. Positive accounting theory. New Jersey: Prentice Hall, 1986.

WELKER, Michael. Disclosure policy, information asymmetry, and liquidity in equity markets. Contemporary Accounting Research, v. 11, p. 801-827, 1995.

YAMAMOTO, Marina; SALOTTI, Bruno. Informação contábil: Estudos sobre sua divulgação no mercado de capitais. São Paulo: Editora Atlas, 2006.

ZHANG, Jidong. Corporate competitive strategy voluntary disclosure and company characters. Social Science Research Network. Disponível em: <www.ssrn.com>. Maio, 2008. Acesso em 22 de Agosto de 2008. 